\title{
Laser Rapid Manufacturing of Stainless Steel 316L/Inconel7 18 Functionally Graded Materials: Microstructure Evolution and Mechanical Properties
}

\author{
Dongjiang Wu, Xiaokang Liang, Qian Li, and Lijia Jiang \\ Key Laboratory for Precision and Non-Traditional Machining Technology of Ministry of Education, Dalian University of Technology, \\ Dalian, Liaoning 116024, China \\ Correspondence should be addressed to Xiaokang Liang, kangkang-1985@163.com \\ Received 7 September 2010; Accepted 13 December 2010 \\ Academic Editor: Giulio Cerullo \\ Copyright () 2010 Dongjiang Wu et al. This is an open access article distributed under the Creative Commons Attribution License, \\ which permits unrestricted use, distribution, and reproduction in any medium, provided the original work is properly cited.
}

Two patterns of functionally graded materials (FGMs) were successfully fabricated whose compositions gradually varied from $100 \%$ stainless steel $316 \mathrm{~L}$ to $100 \%$ Inconel718 superalloy using laser engineered net shaping process. The microstructure characterization, composition analysis, and microhardness along the graded direction were investigated. The comparison revealed the distinctions in solidification behavior, microstructure evolution of two patterns. In the end, the abrasive wear resistance of the material was investigated.

\section{Introduction}

Since the mid-1980s, the processing of Functionally Graded Materials (FGMs) and structures has become an academic interest. They were developed mainly to satisfy the demand of ultra-high-temperature environment and to eliminate the stressed singularities [1]. Recently, they are also developed for various purposes such as abrasive and corrosion wearresistant films to solve any specific tribological problem, and even emphasis on thermoelectric materials for applications in sensors and thermogenerators.

Laser Engineered Net Shaping (LENS) process, as one type of rapid manufacturing technology [2], has demonstrated the capability to produce near-net shape and fully dense metallic parts [3]. This process has been used to deposit a broad range of materials, including stainless steels, nickel-based superalloys, copper alloys, and titanium alloys with enhanced physical and mechanical properties. Several studies have been conducted about fabricating FGMs, and most of them are focused on the traditional FGMs, whose graded direction is parallel to the deposition direction [4].

In this paper, attempts have been made to fabricate two patterns of Stainless Steel 316L(SS316L)/Inconel718 superalloy FGMs by LENS process, which will expand the application of the technology. Also, the microstructure characterization, composition analysis, microhardness, and abrasive wear-resistance along the graded direction are investigated.

\section{Experiments}

In the present study, two patterns of FGM samples with compositions gradually changing from $100 \%$ (volume percent, v/o) SS316L to $100 \%$ Inconel718 are successfully fabricated (30 $\mathrm{mm} \times 1 \mathrm{~mm} \times 36 \mathrm{~mm}, 35 \mathrm{~mm} \times 30 \mathrm{~mm} \times 2 \mathrm{~mm}$, resp.). Figure 1 shows the designed structures of the FGMs.

The LENS system (Figure 2) consists of a $1.2 \mathrm{~kW}$ continuous wave Nd:YAG laser (JK1002), a 3-axis numerical controlled working table, and 3-route powder feeding system. The feedstock materials are injected through a coaxial powder feeding nozzle and delivered by argon gas $(99.999 \%)$ to prevent severe oxidization.

Low-carbon steel $(100 \mathrm{~mm} \times 100 \mathrm{~mm} \times 10 \mathrm{~mm})$ is used as the substrate for the experiment. The compositions of SS316L and Inconel718 powders are listed in Table 1. The processing parameters are presented in Table 2. 


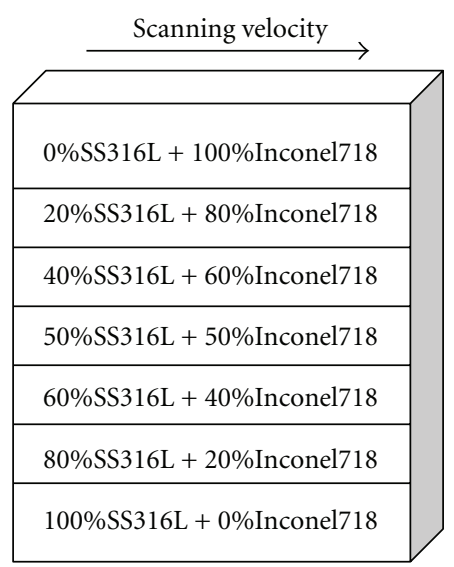

(a) FGM1-tranditional.

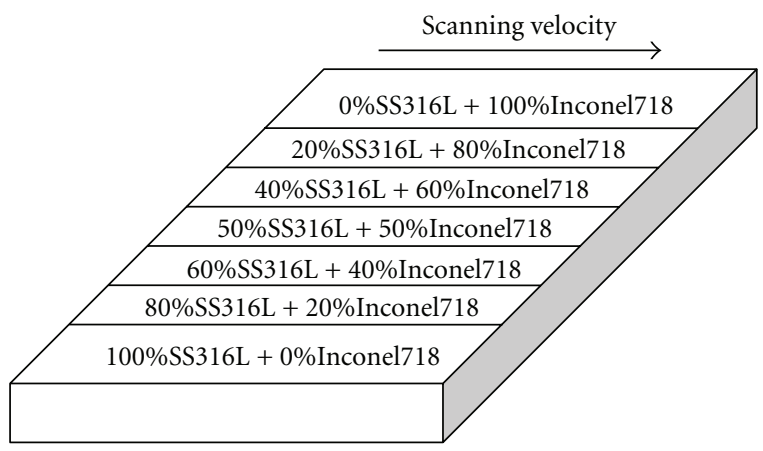

(b) FGM2-novel.

FIGURE 1: Schematic of SS316L/Inconel718 FGMs.

TABLE 1: Chemical composition and size of the powders.

\begin{tabular}{|c|c|c|}
\hline \multicolumn{3}{|c|}{ Chemical composition and size of the powders } \\
\hline Powders & Chemical composition (wt,\%) & $\begin{array}{l}\text { Size } \\
(\mu m)\end{array}$ \\
\hline SS316L & $\begin{array}{l}\leq 0.03 \mathrm{C}, \leq 1.0 \mathrm{Si}, \leq 2.0 \mathrm{Mn}, \leq 0.035 \mathrm{P} \\
\leq 0.03 \mathrm{~S}, 2 \sim 3 \mathrm{Mo}, 12 \sim 15 \mathrm{Ni}, 16 \sim 18 \mathrm{Cr}, \mathrm{Fe} \\
\text { (Bal.) }\end{array}$ & $45 \sim 90$ \\
\hline Inconel 718 & $\begin{array}{l}<0.10 \mathrm{C},<0.75 \mathrm{Si},<0.50 \mathrm{Mn},<0.015 \mathrm{~S} \\
<0.015 \mathrm{P}, 17 \sim 21 \mathrm{Cr}, 50 \sim 55 \mathrm{Ni}, 2.8 \sim 3.3 \mathrm{Mo} \\
0.2 \sim 1.6 \mathrm{Al}, 0.6 \sim 1.3 \mathrm{Ti}, 4.7 \sim 5.5 \mathrm{Nb}+\mathrm{Ta} \\
<0.006 \mathrm{~B}, \mathrm{Fe} \text { (Bal.) }\end{array}$ & $45 \sim 90$ \\
\hline
\end{tabular}

TABle 2: The Laser Processing Parameters.

\begin{tabular}{lc}
\hline Input Variables & Variation Range \\
\hline Laser power $(\mathrm{W})$ & 400 \\
Scanning velocity $(\mathrm{mm} / \mathrm{min})$ & 500 \\
Spot diameter $(\mathrm{mm})$ & 1 \\
Powder feed rate $(\mathrm{g} / \mathrm{min})$ & $4.3 \sim 4.4$ \\
\hline
\end{tabular}

Samples were polished and etched after being cut by wire electron discharge machining. Optical microscope was used to evaluate the microstructure. Quantitative analysis of elemental constituents was determined with electron microprobe (EPMA-1600, with secondary electron resolution as $6 \mathrm{~nm}$ ). The hardness of the sample along the composition

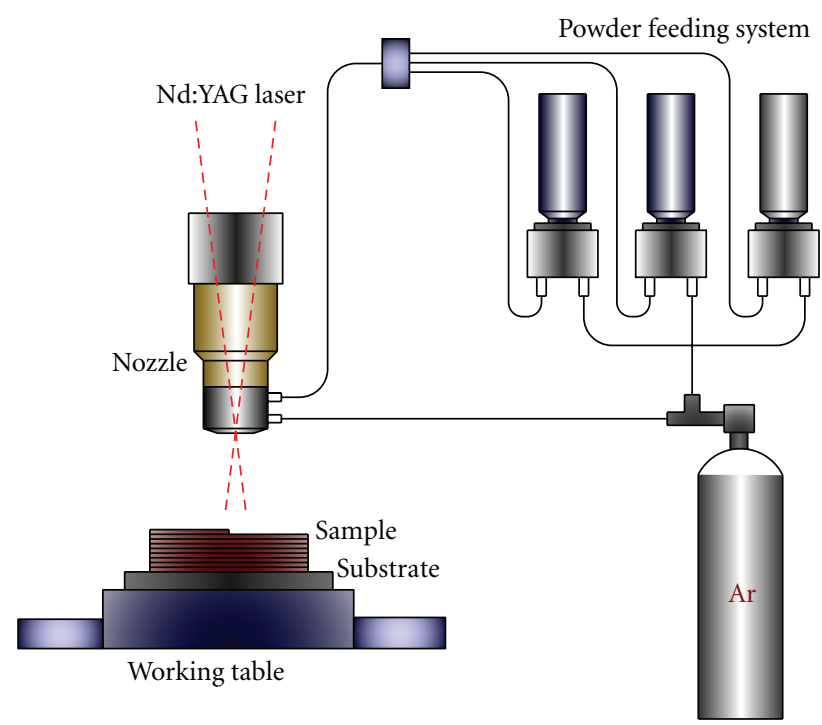

Figure 2: Schematic of of LENS system.

graded was measured by DMH-2LS knoops microhardness tester. The wear properties such as friction coefficient and wear scars were investigated by micro-tribometer (UMT-2).

\section{Results and Discussion}

3.1. Microstructure. Figure 3 shows the microstructure at different locations along the graded direction of FGM1 and FGM2 samples. Various proportions of dendritic, cellular, and columnar structures are visible at different locations in the samples. In some cross-sectional areas, the dendritic grain growth appears to be in random directions, but in particular regions directional solidification could be observed, with strong directional growth in the $\left\langle\begin{array}{lll}1 & 0 & 0\end{array}\right\rangle$ crystallographic direction.

It is indicated that columnar dendritic growth has prevailed in the entire FGM1 sample, except at the edge of the cross-section (Figure 3(b2)), where a columnar to cellular or equiaxed dendritic growth transition is observed. This is due to the increasement of cooling rate and descending of temperature gradient, while in FGM2, the columnar dendritic growth does not appear as dominant as in FGM1.

Figure $3(\mathrm{a})-(\mathrm{c})$ show a distinguishing variation of the primary dendrite arm spacing along the composition graded. As the adding of Inconel718 into the compound, an increasement in primary arm spacing is observed, and dendrites start extending laterally. It is considered to be due to a decrease in temperature gradient as a result of the accumulation of heat as the deposit grew thicker. In FGM2, the primary arm spacing remains constant for its horizontal graded direction. If the texture of the substrate is largely different from the growth direction of the columnar dendrite, a planar growth dark black layer would be obtained (Figure 3(f)). Thus, the continuous epitaxial columnar growth obtained in the material is considered to be due to the condition where the primary dendrite arm spacing is similar to the perturbation wavelength of instability that the planar growth has reached. 


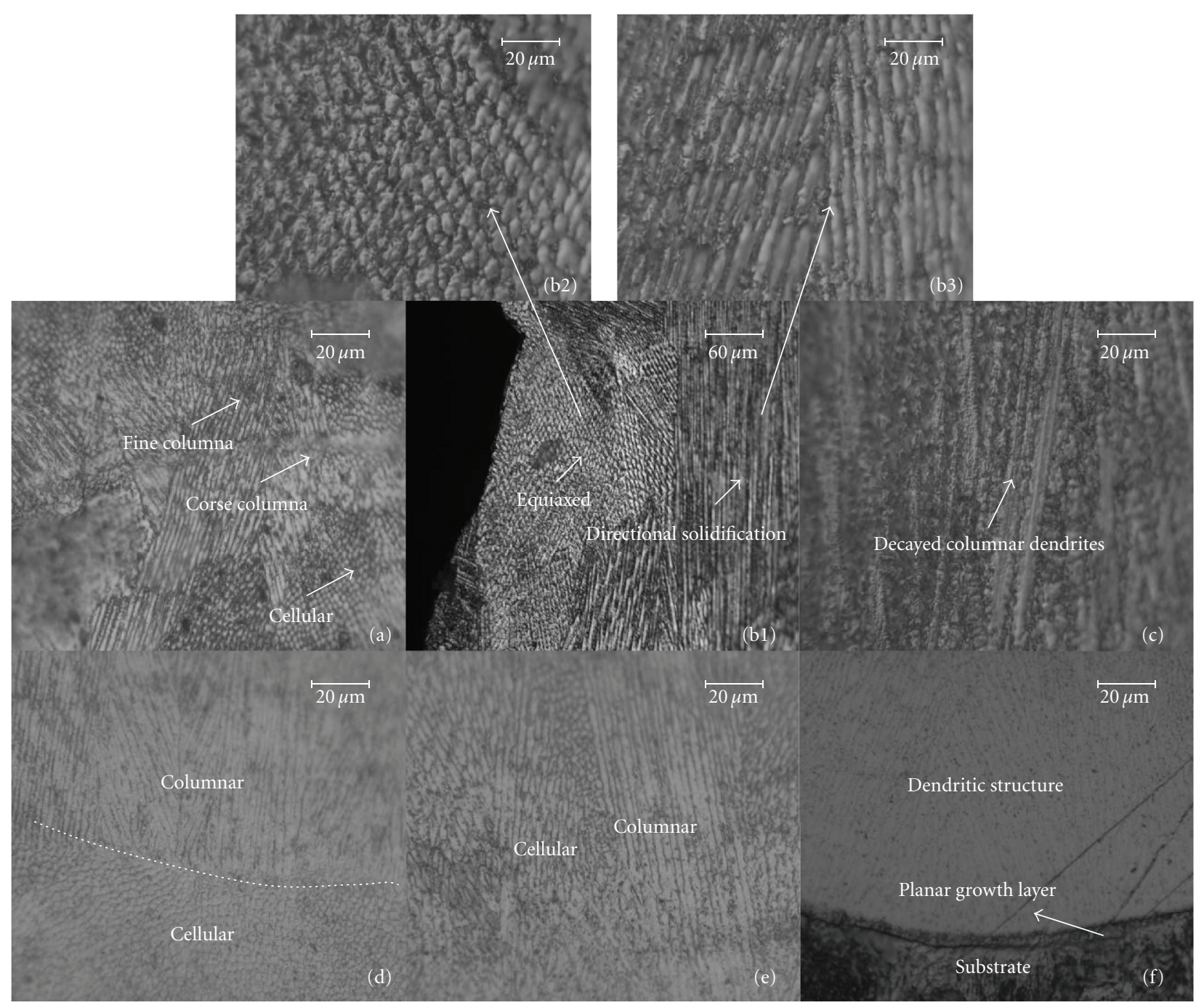

FIGURE 3: Transverse cross-section: (a)-(d) SS316L; (b)-(e) 50\%SS316L+50\%Inconel718; (c)-(f) Inconel718, (a)(b)(c)- FGM1, (d)(e)(f)FGM2.

On the other hand, the growth orientation of the crystals in the melt pool is close to that of the underlying crystals [5].

3.2. Composition. Figure 4 shows the quantitative elemental constituent results of the FGMs. The main elements of SS316L and Inconel718, that is, $\mathrm{Fe}, \mathrm{Ni}, \mathrm{Cr}$, exhibit a good linear relationship along the graded direction. Other elements, such as Mo, Ti, Si, Mn also showed a reasonably good linear relationship. Meanwhile, it is revealed that the average heights of cladding layers vary constantly in FGM1, and this can be related to the increment of $Z$-axis, powder feeding rate, and the corresponding variations of power density. Furthermore, it is suggested that there exists certain diffusions of the elements between the adjacent layers; this kind of diffusion benefits for a perfect bonding between the cladding layers.

3.3. Microhardness. Figure 5 indicates the variation of microhardness along the graded direction in transverse, longi- tude, and normal sections. The microhardness of FGM1 in longitude section drops until it is approximately 40 $50 \mathrm{v} / \mathrm{o}$ Inconel718. Beyond $50 \mathrm{v} / \mathrm{o}$ Inconel718, the hardness increases until pure Inconel718 is fabricated. It can be seen that the microhardness of FGM2 increases continuously along the whole graded direction, whether in normal section or in transverse section.

Just as the former discussion the microstructure of FGM2 in transverse section is rich in directional growth columnar dendrites (Figure 3(d)-(f)), and the microstructure of FGM2 in normal section is rich in cellular dendrites, which will lead to the comparative decreased hardness (approximately $50 \mathrm{HK}$ ). Meanwhile, the microstructure in FGM1 exhibits a columnar (lower part, $0 \sim 50 \mathrm{v} / \mathrm{o}$ Inconel 718 ) to cellular or equiaxed (upper part, beyond $50 \mathrm{v} / \mathrm{o}$ ) transition, which will lead to a similar condition of microhardness just like the change from transverse section to normal section in FGM2.

It is considered to be due to the "ferritic-austenitic solidification mode" [6] that leads to the decrease of hardness in FGM1 $(0 \sim 50 \mathrm{v} / \mathrm{o})$. With the adding of Inconel718, 


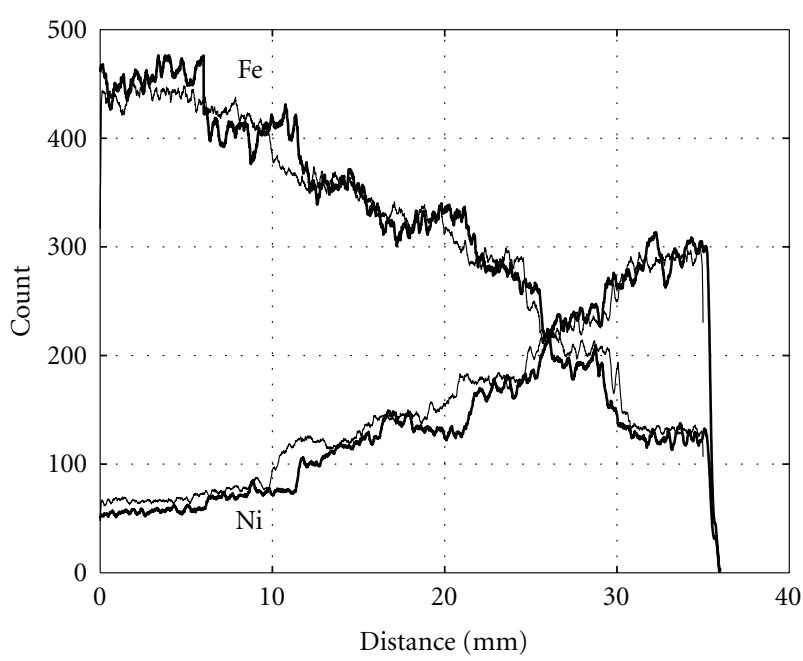

(a)

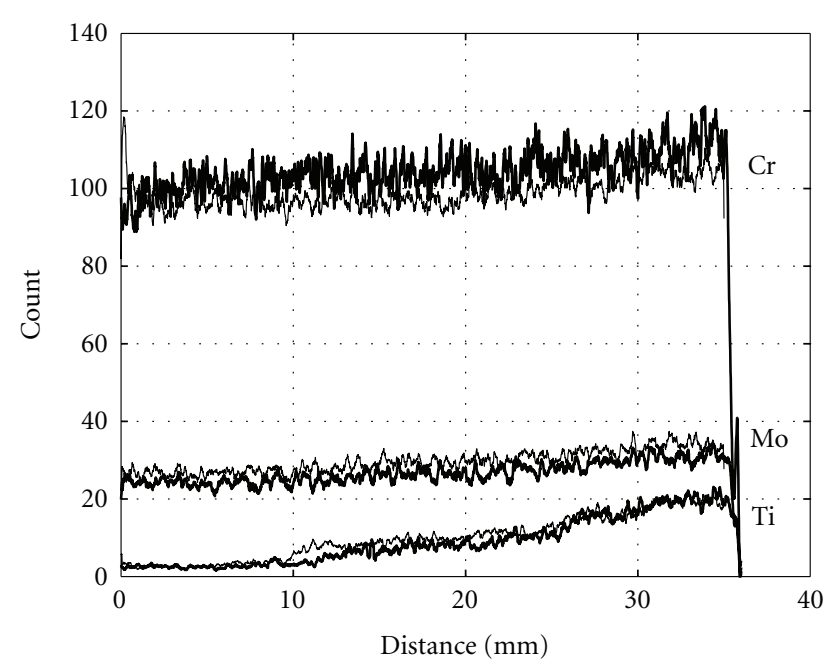

(b)

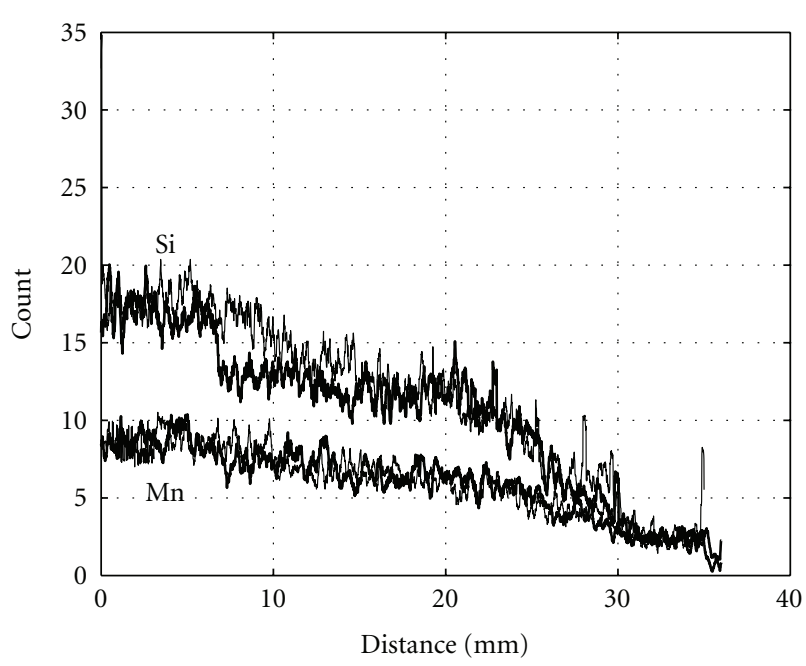

- FGM1

- FGM2

(c)

FIgURE 4: The compositional distribution.
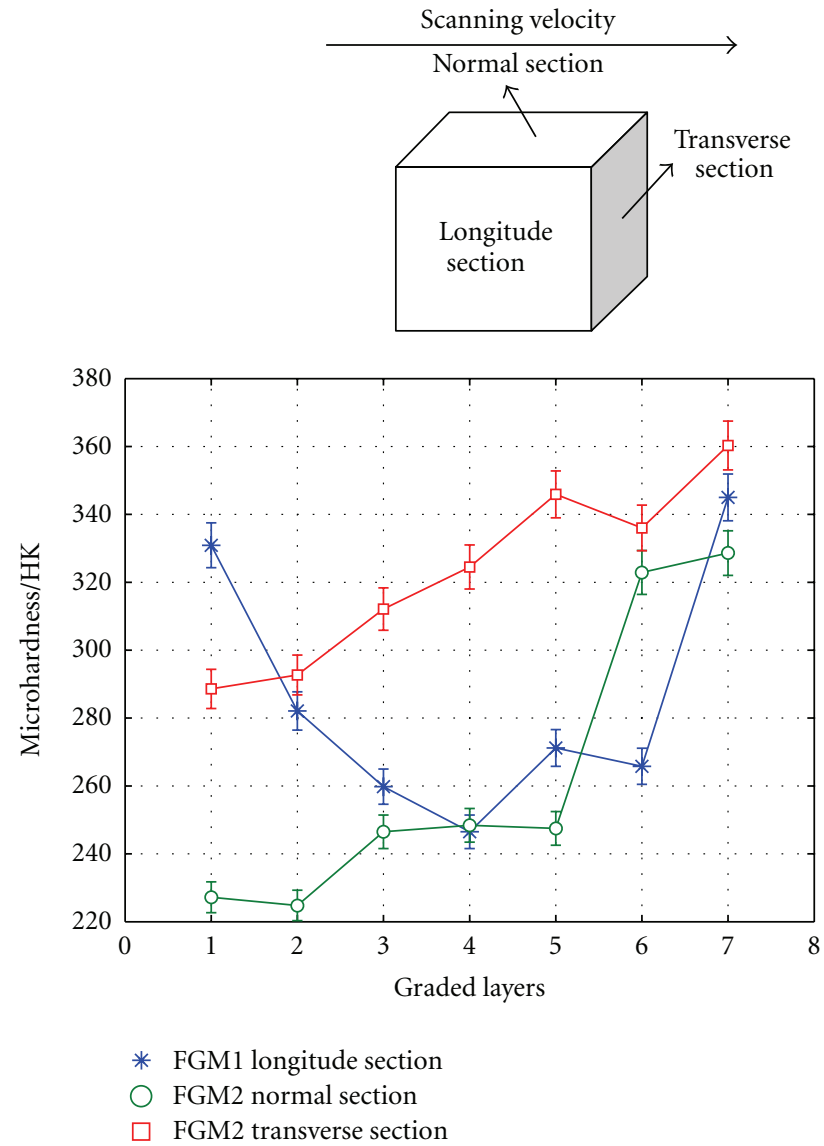

FIGURE 5: The microhardness along the graded direction.

the microhardness increases continuously in both FGM1 $(50 \sim 100 \mathrm{v} / \mathrm{o})$ and FGM2. This is because with the adding of Inconel718, the content of $\mathrm{Cr}$, Mo, and so forth increases, resulting in the reinforcement of solid solution strengthening effect. On the other hand, the precipitation strengthening effect of elements, such as $\mathrm{Ti}, \mathrm{Al}, \mathrm{Nb}$, plays a crucial role in the hardness and other mechanical properties.

3.4. Friction Wear Behaviors. Figure 6 shows the friction coefficient and width of wear scars along the graded direction in FGM2. It is indicated that the friction coefficients increase gradually along the graded direction, with the values of 0.4342 in $100 \%$ SS316L and 0.6989 in $100 \%$ Inconel718. It can be seen that the damages in $100 \%$ SS316 L and $100 \%$ Inconel718 are slightly different, with the wear width of $364.4 \mu \mathrm{m}$ and $354.5 \mu \mathrm{m}$, respectively. In the graded zone, the damage seems much more severe. There exists plastic deformation, plough, and tears in the wear scars.

Micro cutting mechanism predominates in the dry sliding condition, accompanied by adhesive wear. It can be due to the lower friction coefficient and the deformationinduced phase change that results in the slight damage in $100 \%$ SS316L. Meanwhile, the elements of N, Mn can lower the stacking fault energy of austenite stainless steel; this will enhance the ability to defend the deformation. With 


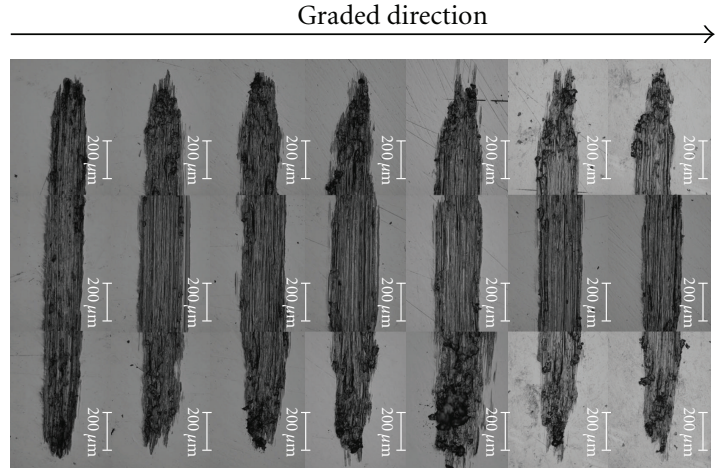

(a)

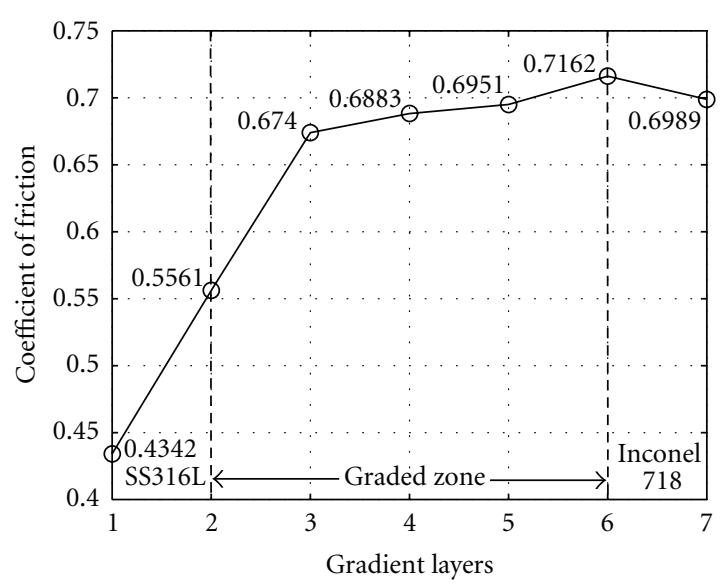

(b)

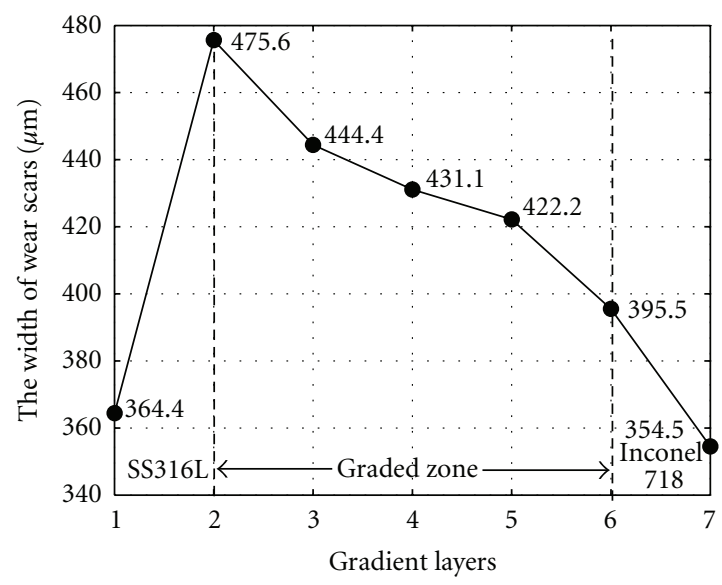

(c)

FIGURE 6: The wear properties of FGM2: (a) wear scars; (b) friction coefficient; (c) width of wear scars.

the adding of Inconel718, brittleness such as carbide particles and intermetallic compounds formed, which will flake easily during the friction. It can be seen in the graded region that the flake brings about the abrasive wear such as the plough and tear, leading to a severe damage. It is considered to be due to the inherent high microhardness $(328.6 \sim 360.3 \mathrm{HK})$ that makes $100 \%$ Inconel718 keeping the excellent wearresistance, although the friction coefficient is much higher than other layers.

\section{Conclusions}

In the present study, linear composition graded materials of Stainless Steel 316L/Inconel718 superalloy in two patterns have been fabricated using LENS process. The study may expand the scope of FGMs prepared by LENS technology. The microstructure in FGM1 exhibits a columnar to equiaxed transition. It indicates a change of solidification mode in FGM1, and the microhardness shows a corresponding decrease between $0 \sim 50 \mathrm{v} / \mathrm{o}$; while the microhardness exhibits a good linear increase in FGM2. In the end, the friction wear behavior of FGM2 is investigated, indicating that both $100 \% 316 \mathrm{~L}$ and $100 \%$ Inconel718 layers are with excellent wear-resistance.

\section{Acknowledgments}

This research paper was supported by the National Key Basic Research Program of MOST (Grant no. 2009CB724307), Specialized Research Fund for the Doctoral Program of Higher Education of Ministry of Education (Grant no. 20070141002).

\section{References}

[1] A. Kawasaki and R. Watanabe, "Thermal fracture behavior of metal/ceramic functionally graded materials," Engineering Fracture Mechanics, vol. 69, no. 14-16, pp. 1713-1728, 2002.

[2] G. N. Levy, R. Schindel, and J. P. Kruth, "Rapid manufacturing and rapid tooling with layer manufacturing (LM) technologies, state of the art and future perspectives," Annals of the CIRP, vol. 52, no. 2, pp. 589-609, 2003.

[3] G. P. Dinda, A. K. Dasgupta, and J. Mazumder, "Laser aided direct metal deposition of Inconel 625 superalloy: microstructural evolution and thermal stability," Materials Science and Engineering A, vol. 509, no. 1-2, pp. 98-104, 2009.

[4] K. H. Shin, H. Natu, D. Dutta, and J. Mazumder, "A method for the design and fabrication of heterogeneous objects," Materials and Design, vol. 24, no. 5, pp. 339-353, 2003.

[5] X. Lin, T. M. Yue, H. O. Yang, and W. D. Huang, "Laser rapid forming of SS316L/Rene88DT graded material," Materials Science and Engineering A, vol. 391, no. 1-2, pp. 325-336, 2005.

[6] M. L. Griffith, L. D. Harwell, J. T. Romero, E. Schlienger, C. L. Atwood, and J. E. Smugeresky, "Multi-material processing by LENSTM," in Proceedings of the Annual International Solid Freeform Fabrication Symposium, 1997. 

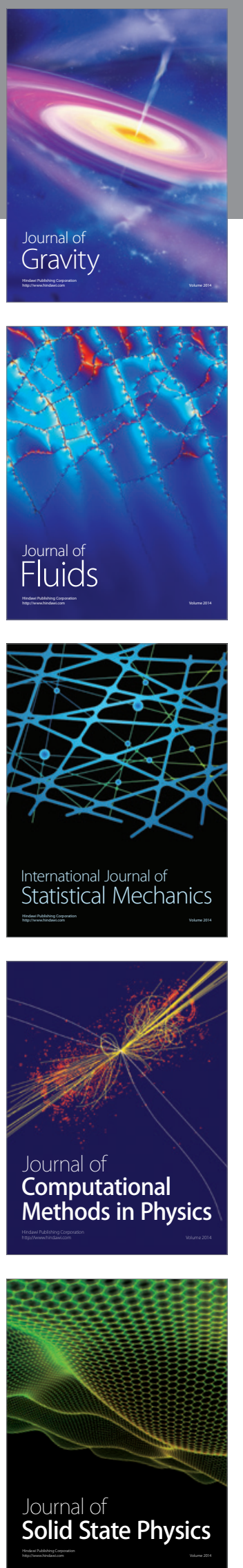

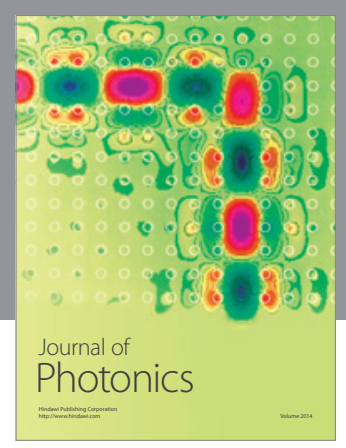

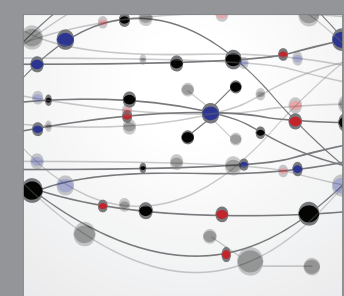

The Scientific World Journal
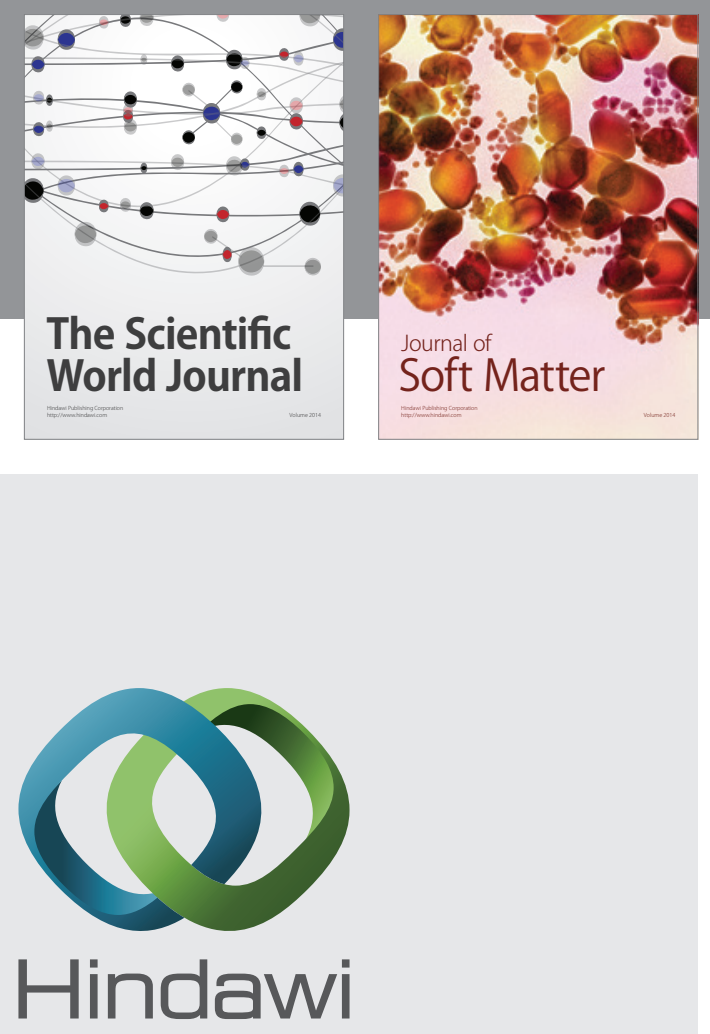

Submit your manuscripts at

http://www.hindawi.com
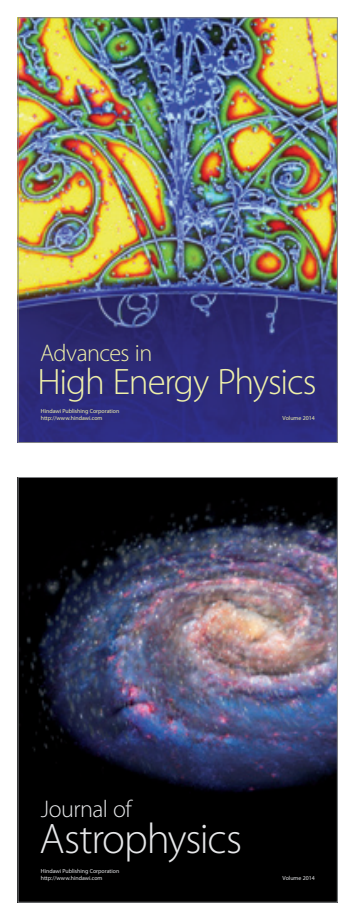
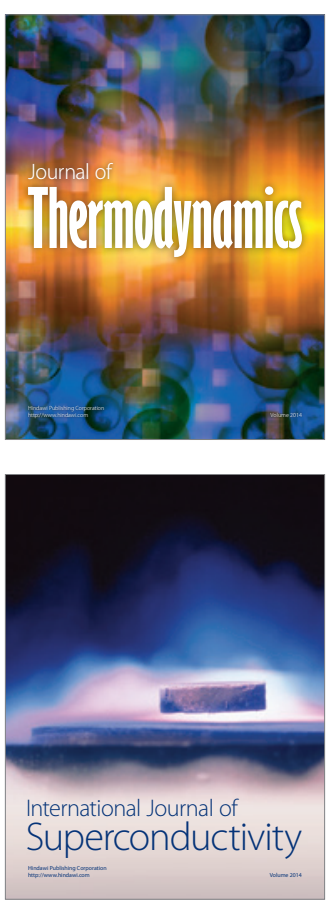
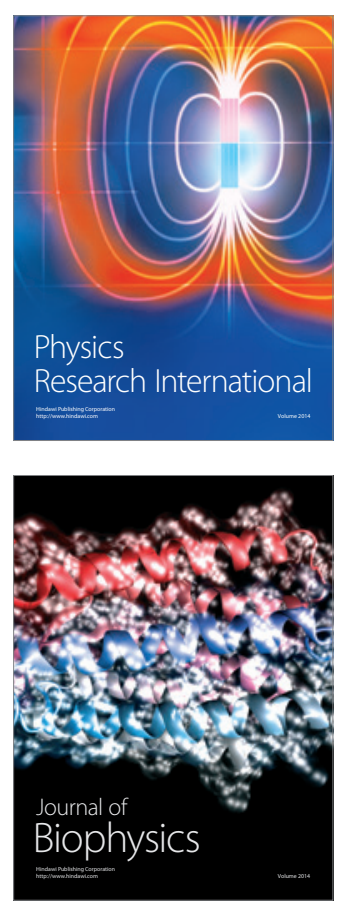
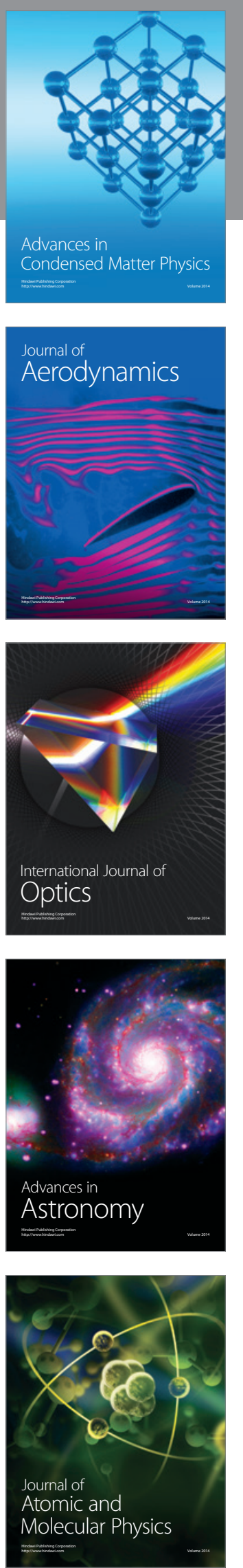